RESEARCH PAPER

\title{
Recent trends in home and work smoking bans
}

\author{
D T Levy, E Romano, E A Mumford
}

Tobacco Control 2004;13:258-263. doi: 10.1136/tc.2003.006056

See end of article for authors' affiliations

....................

Correspondence to:

David T Levy, PhD, 14403

Sylvan Glade Drive, North

Potomac, MD 20878,

USA; levy@pire.org

Received

11 September 2003

Accepted 10 March 2004

\begin{abstract}
Objectives: Home and work smoking bans at the national and state level in the USA, and their relation to smoking prevalence and to tobacco control policies, are examined.

Data: The Current Population Survey's 1992/93 and 1998/99 tobacco use supplement surveys are the primary data source, supplemented with information on state level tobacco control policies.

Methods: The national and state rate of bans are estimated, and changes over the course of the 1990s and their relation to smoking rates and tobacco control policies are examined.

Results: The prevalence of work and home bans has increased considerably between 1992/93 and 1998/99. By 1999, over $65 \%$ of the population age 15 and above work in places with smoking bans, and over $60 \%$ live in homes with bans. We found that states with lower than average ban rates in 1993 tended to have had larger increases in ban rates between 1993 and 1999. We also found that home and work bans became more prevalent in states with initially low smoking rates, and that the growth in home bans coincided with a declining prevalence of smoking. States with higher levels of bans by 1999 also tended to have higher cigarette taxes, stricter clean air laws, and media/comprehensive campaigns in place.

Conclusions: The results indicate that lower smoking rates are associated with higher rates of work and home bans, although substantial progress has also been made by those states with initially low rates of bans. While further work is needed to establish the direction of causality, it would appear that reductions in smoking rates, either through stronger tobacco control policies or otherwise, may reduce exposure to tobacco smoke not only by reducing the number of smokers, but also through increasing the number of firms and homes with smoking restrictions.
\end{abstract}

S econdhand smoke has been found to increase the risk to non-smokers of lung cancer, heart disease, sudden infant death syndrome, and many other diseases. ${ }^{1-3}$ Concerns about these health risks and their costs have justified limits to smoking in the presence of non-smokers. Evidence indicates substantial increases in bans on smoking in private work places, ${ }^{4-6}$ and these bans have been associated with reduced secondhand smoke exposure. ${ }^{78}$ Home bans also reduce exposure. ${ }^{9}$ The prevalence of home bans has increased considerably in places as far apart as Australia $^{10}$ and California. ${ }^{11}$ In the USA, the rate of home bans is at high levels in many states. ${ }^{6}{ }^{12}$

In this paper, we consider national and state trends in home and work bans over most of the 1990s in the USA. We use a nationally and state representative dataset that provides comparable measures for two time periods, 1992/93 and 1998/99, referred to throughout this paper as the years 1993 and 1999.

We also examine differential patterns in the growth of ban rates among states. In particular, we consider whether the growth in the rate of home and work bans reflects a catch-up phenomenon, in which states with initially lower rates of smoking bans had more growth in the rate of bans. Alternatively, states with low and/or decreasing smoking rates may have had the higher growth rate in bans. In particular, smoking rates are likely to reflect attitudes toward smoking as well as the cost and convenience of smoking. ${ }^{13}$ Consequently, we would expect that states with lower smoking rates may be responsible for the greater amount of growth in smoking bans. To the extent that changes in smoking rates reflect changes in norms, smoking bans may also become more acceptable as an effective means to protect the health of non-smokers. ${ }^{12} 14$

Besides considering the growth in work and home bans across states, we also consider how the level of home and work smoking ban rates are related to tobacco control policies. Reflecting our expectations of an impact on norms and cost/ convenience from a range of tobacco control policies, we expect that privately implemented home and work smoking bans will increase with stronger public tobacco control policies.

\section{METHODS}

\section{Data sample}

The US Current Population Survey's tobacco use supplement is the primary source of data. A probability sample employs stratified clusters of households drawn from an initial sampling frame that covers the civilian, non-institutionalised population ages 15 and older. Primary data collection was conducted by telephone but about $25 \%$ of interviews were conducted in-person in the household. We exclude answers by proxy, since only self responders were eligible to answer most of the tobacco use questions.

The sampling procedure of the tobacco use supplement data was developed with the intent of creating state as well as nationally representative data. For each of the measures below, we create national and state level measures. We separately examine data for two sample years: 1992/93 and 1998/99, referred to throughout this paper as the years 1993 and 1999. The data for each of the two sample years consisted of three samples collected in September (previous year), January, and May. Following the survey administrators' recommendation, the data from these three waves were aggregated into a single data file.

\section{Smoking restrictions at home and work and smoking rates}

The tobacco use supplement asked at least one member of each household, "Which best describes the rules about smoking in your home?" We limit our analysis to "strict bans", where strict bans are associated with no smoking allowed anywhere in the house or at any time. While some research indicates that the level of restriction is relevant to outcomes, the evidence generally indicates that strict bans 


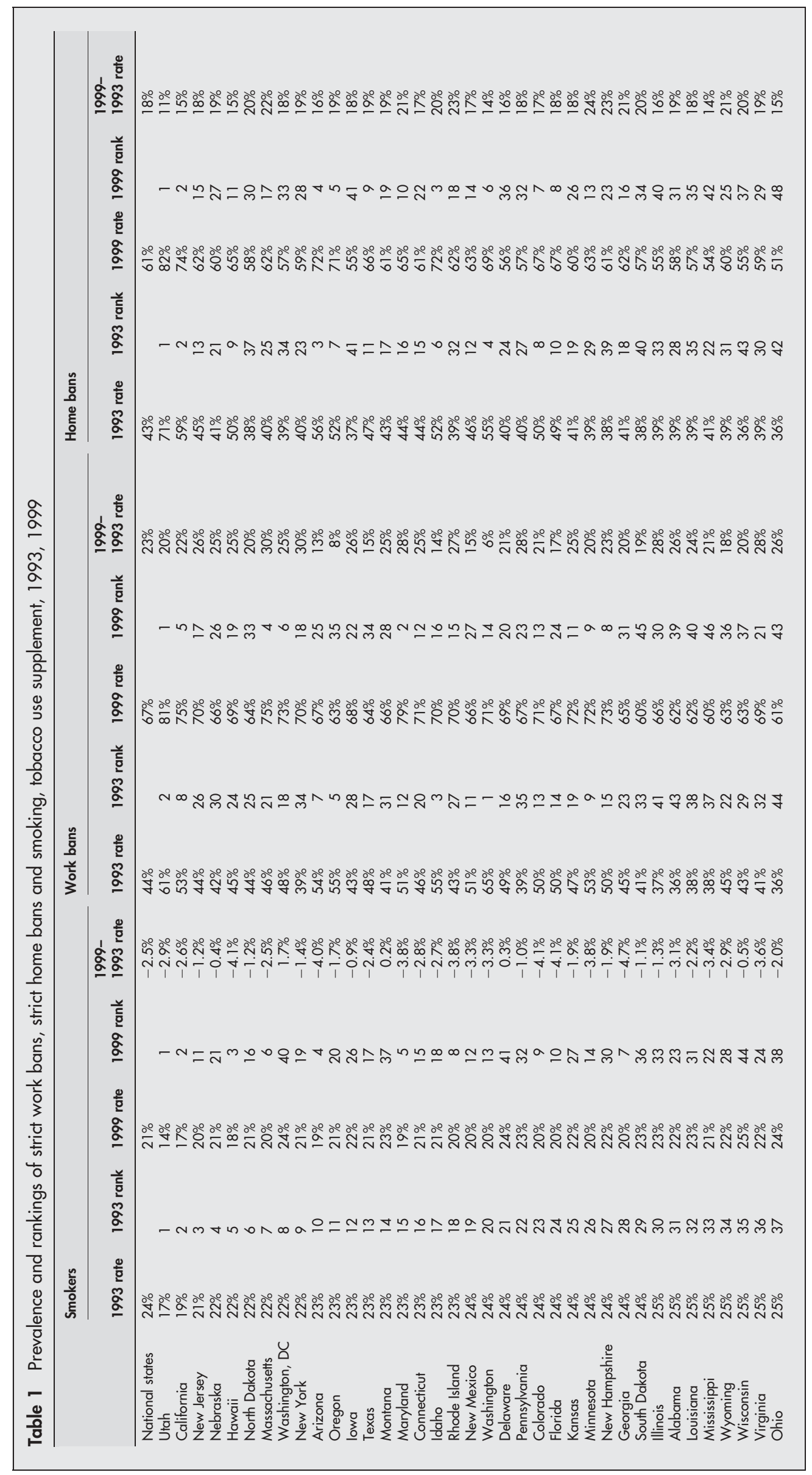




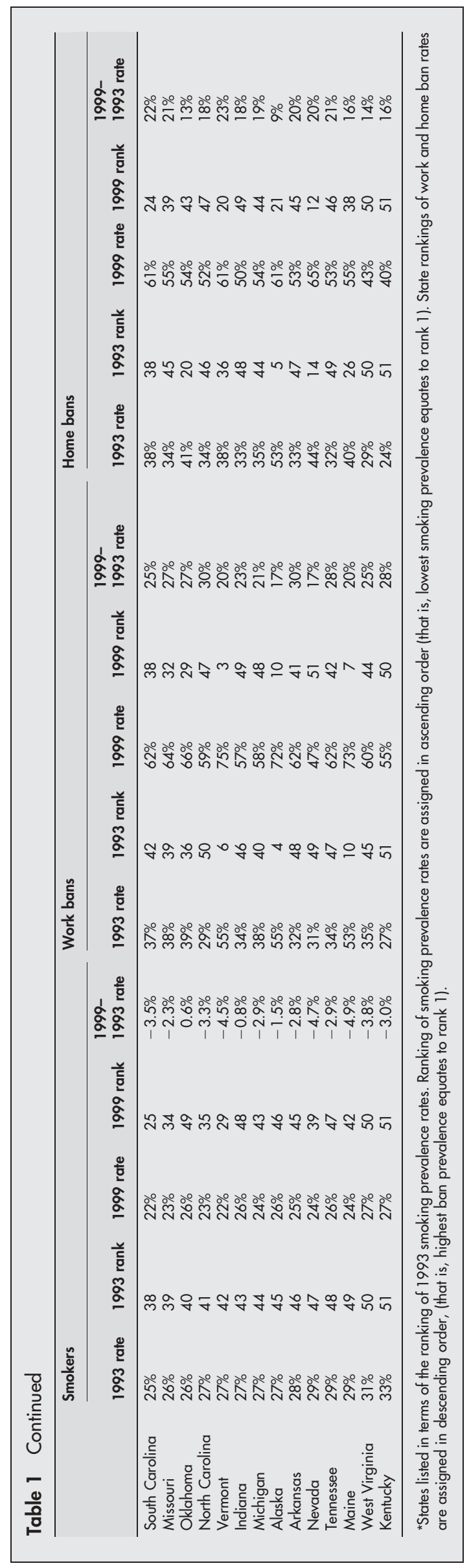

are more effective. ${ }^{15-19}$ In addition, a Report of the US Surgeon General $^{20}$ found that separating smokers and nonsmokers in the same space may reduce, but clearly did not eliminate secondhand smoke exposure. Therefore, we limit our analysis to strict bans, defined as no smoking allowed anywhere in the house.

Those respondents in the tobacco use supplement sample who worked indoors and who were not self employed (about one third of the sample) were asked whether their workplace had policies banning smoking in working areas and common areas. We examined strict bans defined as banning smoking both in working areas and common areas. Evidence again suggests that weaker bans have a substantially smaller effect. ${ }^{152122}$ At the national and state level, the rate of work bans was defined as the percentage of the population age 15 and above that worked indoors and were not self employed who were subject to a strict smoking ban at work.

A "current smoker" was defined as someone who had smoked at least 100 cigarettes and who at the time of the survey was smoking some days or all days in the last month. At the national and state level, the smoking prevalence was defined as the percentage of the population age 15 and above who were current smokers.

For each of the above variables, separate rate measures were created for 1993 and 1999. We also created variables to measure the percentage point change (that is, absolute difference) in the rates between the years 1993 and 1999.

\section{Tobacco control policies}

Of public tobacco control policies, taxes, clean air restrictions, and media/comprehensive campaigns have shown the most consistent relation to smoking rates..$^{202-25}$ Variables for each policy reflect state levels, and were collected from sources other than the tobacco use supplement. Data on the tax per pack by state in November 1998 are obtained from Orzechowski and Walker. ${ }^{26}$ We used a scale of state clean air laws developed by Chriqui et al, ${ }^{27}$ and downloaded from http://www.scld-nci.net, that includes each of seven site specific smoking restrictions (public worksites, private worksites, schools, childcare facilities, restaurants, retail stores, and recreational/cultural facilities), and two enforcement related items. The presence of media campaigns/comprehensive tobacco policies (based on data supplied by the Centers for Disease Control and Prevention (CDC) and confirmed through state websites) was measured as an indicator variable, indicating whether the state had begun a media campaign. California, which had implemented a media campaign as early as 1989, was the only state that had a media campaign in place by early 1993. Massachusetts and Arizona also had campaigns in place by 1996. By early 1999, Florida, Utah, and Oregon had implemented campaigns. ${ }^{25}$

\section{Statistical methods}

We estimated the prevalence of work bans, home bans, and current smokers for the nation and by state. We weight the national and state data by the self report weights supplied by the tobacco use supplement to get national and state estimates.

In addition to comparing trends over time, we examine state rankings. Based on differences in trends across states, we estimated linear regression equations (separate equations for home and work bans) that examine absolute changes in the ban rates between 1993 and 1999. To test whether there was a catch-up phenomenon among states with initially lower rates of bans, we included a variable indicating the initial level (for example, the level of home bans in 1993 in the equations explaining changes in home bans between 1993 and 1999). At the same time, we included variables for 
Table 2 Regression analysis of the change in ban rates, 1999-1993, tobacco use supplement, state level data

\begin{tabular}{|c|c|c|c|c|c|c|}
\hline \multirow[b]{2}{*}{ Dependent variable } & \multicolumn{3}{|c|}{ Work bans (1999-1993) } & \multicolumn{3}{|c|}{ Home bans (1999-1993) } \\
\hline & Coefficient & $t$ Stat & p Value & Coefficient & t Stat & p Value \\
\hline \multicolumn{7}{|l|}{ Independent variable } \\
\hline Ban rate 1993 & -0.64 & -8.59 & 0.00 & -0.39 & -5.91 & 0.00 \\
\hline Smoke rate 1993 & -0.82 & -3.37 & 0.00 & -0.90 & -4.45 & 0.00 \\
\hline Smoke rate 1999-1993 & -0.30 & -0.74 & 0.46 & -1.07 & -3.77 & 0.00 \\
\hline Constant & 0.78 & 8.73 & 0.00 & 0.54 & 7.69 & 0.00 \\
\hline$R^{2}$ & 0.64 & & & 0.45 & & \\
\hline
\end{tabular}

Table 3 Regression analysis of the level of ban rates in 1999, tobacco use supplement state level data

\begin{tabular}{|c|c|c|c|c|c|c|}
\hline & \multicolumn{3}{|l|}{ Work bans } & \multicolumn{3}{|l|}{ Home bans } \\
\hline & Coefficient & $t$ Stat & p Value & Coefficient & $t$ Stat & p Value \\
\hline \multicolumn{7}{|c|}{ Policy equations } \\
\hline Tax & 0.003 & 1.98 & 0.05 & 0.002 & 1.42 & 0.16 \\
\hline Media & 0.290 & 2.23 & 0.03 & 0.460 & 3.92 & 0.00 \\
\hline Clean air & 0.207 & 3.67 & 0.00 & 0.012 & 1.79 & 0.08 \\
\hline$R^{2}$ & 0.44 & & & 0.43 & & \\
\hline
\end{tabular}

The equation explains the work (home) ban rates in 1999 by the tax rate, the existence of a comprehensive/media campaign, and the extent of clean air laws. The analysis is conducted at the state level (50 observations).

the initial level of the smoking prevalence and concurrent changes (between 1993 and 1999) in the smoking prevalence.

Having assessed developments in ban rates over the 1990s and the role of smoking prevalence, we focused on the association between bans and tobacco control policies in 1999. We estimated equations predicting the level of ban rates in 1999 with contemporaneous tobacco control policies. These equations are reported below.

All analyses are conducted using SAS, version 8.02. The District of Columbia is excluded from the regression analysis because many of the residents work in neighbouring states. Because we view each state as a single observation, we do not weight the observations in the regression analyses. Weighting by population would have the effect of large states swamping the effects of small states in the regression analysis.

\section{RESULTS}

\section{National}

The data in table 1 first shows the rate of home and work bans in the nation for 1993 ( $\mathrm{n}=236809$ self respondents) and 1999 ( $\mathrm{n}=182224$ self respondents). The rate of strict work bans among indoor workers increased from $43.6 \%$ in 1993 to $66.8 \%$ in 1999 , or an increase of 23.2 percentage points. Home bans increased from $43.1 \%$ in 1993 to $61.1 \%$ in 1999 , or an increase of 18.0 percentage points from 1993. When we examined data from 1995/96 (not shown), we found that home bans increased quite uniformly between 1993 and 1999, but work bans increased three times as much in the earlier part of the decade (17.6 percentage points between 1993 and 1996) as in the latter (5.6 percentage points between 1996 and 1999).

\section{By state}

Table 1 shows the rate of work and home bans and of smoking prevalence by state for 1993 and 1999, the changes between those two years, and the state rankings in 1993 and 1999. The states are ranked by their smoking prevalence from lowest to highest in 1993.

In 1993, work bans ranged from $27.2 \%$ in Kentucky to $64.5 \%$ in the state of Washington. By 1999, the range had narrowed slightly with a high of $81.4 \%$ in Utah and a low of $47.2 \%$ in Nevada. Generally, most states increased their prevalence of work bans between 1993 and 1999, and thus the rankings were generally stable over the period with some exceptions. Maryland, which implemented a strict worksite clean air law in 1994, and Massachusetts, which began a comprehensive tobacco control programme in 1999, improved their positions throughout the 1990s. Between 1993 and 1999, many of the states with initially low rates of work bans, including Arkansas, New York, North Carolina, Oklahoma, and Tennessee, moved toward the median, with large absolute percentage point and even larger percentage increases in work bans than many of the states with a higher 1993 work ban rate. For example, Arkansas went from 31.6\% of workers to $61.7 \%$ of workers subject to work bans, and increased their rank from 48 to 41. Arizona, Idaho, Oregon, and Washington each increased their ban rates by at least $10 \%$, but their rankings fell, because their ban rates were among the highest in 1993.

Similar results were obtained for home bans. In 1993, the rate of strict home bans ranged from in to $24.2 \%$ in Kentucky to $71.0 \%$ in Utah. The gap had narrowed slightly by 1999 , with Kentucky at $39.7 \%$ and Utah at $81.7 \%$. Nevertheless, rankings did not change much between the states. Most states increased their rates of home bans between 13\% and $22 \%( \pm 5 \%$ of the national average). The exceptions were Utah and Alaska, which both had high rates in 1993 and increased by less in subsequent years.

Table 1 also presents the smoking prevalence and rankings and (from lowest to highest) for the states. It can be seen that those states with lowest smoking rates generally have the highest rates of work and home bans.

\section{Changes in smoking bans over time}

Models of the changes in the rate of work and home bans between 1993 and 1999 are presented in table 2. We found that the initial level of the work ban rate was negatively related to future changes in that rate, consistent with the observation above that states with initially lower levels of work bans in 1993 had greater increases in subsequent years. We found that the change in the rate of work bans was negatively related to the initial level of smoking rates, indicating that states with lower baseline smoking rates also tended to show a greater increase in the rate of work bans. The analysis does not indicate a clear 
relation between concurrent changes in the prevalence of smoking bans and current smoking. We obtained similar results for home bans, except that concurrent changes in smoking rates were negatively related to the change in home smoking bansthat is, a larger decline in smoking prevalence was associated with a more rapid increase in home bans. We also estimated equations that examined changes between 1993 and 1996 and between 1996 and 1999 (not shown), and obtained similar results.

\section{The 1999 level of smoking bans and tobacco control policies}

In table 3, we present models of the 1999 state levels of smoking restrictions at home and work, respectively, examining the relation with contemporary tobacco control policies. Included as a set, the tax, media, and clean air measures for 1999 all were significantly related to the 1999 level of work bans. In the home ban equation, only the media coefficient was significant at conventional levels. When the tax, media, and clean air laws variables were entered one at a time into separate equations for work and home bans, we found that they were in all cases significant at the 0.05 level. This variation in results with policy variables entered separately relative to equations with the variables entered jointly is indicative of the high degree of collinearity between the policy variables.

\section{DISCUSSION}

This study employs a large nationally and state representative dataset of individuals to examine the changing landscape of home and worksite smoking bans. We consider the relation of both types of restrictions to smoking prevalence over the 1990s, and to selected tobacco control policies (tax, clean air and media) in 1999.

At a national level, the rate of both strict work and home smoking bans increased between 1993 and 1999. The rate of home and work smoking bans also increased in individual states, although at different rates. We found that states with lower initial rates often had larger absolute increases in these rates, even though they often had a higher smoking prevalence. Such a finding supports our catch-up hypothesis. Although the data precluded us from testing the relevance of different possible causes leading to this outcome, we speculate that states with lower ban rates may have been more influenced by publicity and norm changes during the 1990s compared to states that had already changed norms. In some states with initially high ban rates, such as California and Massachusetts, active tobacco control policies had been in effect, and in other states, such as Arizona and Oregon, grass roots support for tobacco control had also been strong by 1993. At higher initial ban rates, it may also be more difficult to make further progress in establishing or strengthening smoking restrictions. Some types of businesses may be reluctant or the presence of smokers within households may limit opportunities for restrictions. Of note, there is a potential bias if some individuals, such as smokers, are less likely to report the existence of bans. For example, Mumford et $a l^{28}$ found that $12 \%$ of multi-member households gave discrepant answers on whether they were subject to a strict ban, and households with a smoker were $60 \%$ more likely to provide a discrepant response compared to households without a smoker.

A central finding in this paper is that states with greater growth in home and work smoking bans were those with the lower smoking prevalence. We also found that reductions in smoking prevalence were associated with greater growth in home bans. The absence of a similar relation between changes in smoking prevalence and work bans may reflect the greater challenges of implementing smoking restrictions in the workplace than at home. Although it is not clear whether reduced smoking prevalence is a necessary agent for growth in smoking restrictions, or whether the implementation of smoking bans simply tends to lag declines in smoking prevalence, in either case, the opportunity to protect nonsmokers expands with the growth of home and work bans.

We also found that the intensity of tobacco control policies was related to home and work bans in 1999. Shopland et al ${ }^{4}$ previously found a correlation between the strictness of state clean air laws and the presence of strict work bans; Moskowitz et a ${ }^{29}$ found that communities in California with stricter laws had a higher percentage of firms with strict bans. Besides the direct effect of clean air laws requiring stricter workplace bans, public policies may affect privately implemented bans through a change in norms toward an anti-smoking sentiment. ${ }^{20}$ Media campaigns, in particular, may be used to increase knowledge about the dangers of secondhand smoke. Norman et $a^{30}$ found that adult smokers having greater exposure to the California Tobacco Control Program were more likely to have home smoking bans.

While concurrent tobacco control policies were found to be associated with the level of bans, in examining the relation between earlier policies and subsequent changes in ban rates we were not able to distinguish a policy effect, except through clean air laws in some specifications of the model (not shown). The timing of changes in policies may be important and may not have been adequately captured by the measures. For example, California had already had media policies in effect as of 1989, while other states had policies in effect later. In addition, there were few major changes in tobacco control policy in most states during the 1990s. In recent years, several states, including Delaware, Florida, and New York, have implemented strong work site laws. Tracing the effects of these laws may help untangle the effects of clean air laws on home and work bans.

Another potential problem in the estimation equations may be measurement error in the policy variables. Our measures of clean air laws were based on state laws, but some states have counties or cities that have stricter clean air laws than at the state level. The media measure also may not have adequately captured local variations, as well as differences in the extent (for example expenditures per capita) and focus of media policies at the state or local level. The included policy variables also may not capture the range of different policies (including types of clean air laws) that are implemented in different states and at the community level.

A fundamental problem in determining the relation between smoking bans and tobacco control policies and between bans and smoking rates is in distinguishing the causal relation. In California, home and work bans appear to have continued increasing although smoking prevalence has changed little between 1994 and 1999. ${ }^{11}$ However, in Arizona, the rate of home and work bans was high before comprehensive policy measures were taken, and did not change much afterwards. Because this study involves cross sectional data of levels or changes over short periods of time, caution is warranted in attributing causality to the relationship. In particular, home smoking bans may reflect underlying social norms and attitudes toward smoking that have led to both the implementation of stricter public policies and a greater rate of the bans. Such a simultaneous effect has not been explicitly considered by this study and may bias the results.

The results above were relatively robust over various specifications of the models. The results were generally consistent when we considered bans affecting specific age groups, especially for individuals older than 25 years. The results were generally as strong or stronger when we considered the rate of bans for only the smoking population as when we 


\section{What this paper adds}

Secondhand smoke from cigarettes is known to increase the health risks to non-smokers. Bans on smoking have been implemented in homes and in the workplace to reduce these risks. Past studies have examined which homes and worksites implement these bans, but studies have not considered the factors associated with the overall growth in the rate of home and work bans. This paper considers national and state trends in home and work bans over most of the 1990s in the USA.

Home and work bans became more prevalent in states with initially low ban rates and smoking rates, and the growth in home bans coincided with a declining prevalence of smokers. States with stricter tobacco control policies also had higher rates of bans. The results suggest that efforts to reduce smoking rates may reduce exposure to tobacco smoke not only by reducing the number of smokers, but also through increasing the number of firms and homes with smoking restrictions.

considered the entire population, although reported ban rates are lower among smokers. We estimated equations using log odds ratios for the dependent variable and obtained similar results. We also calculated a variable of smoking intensity, measured by the average number of cigarettes smoked per day by smokers within the state. That variable was correlated with the change in bans between 1993 and 1999 and the 1999 level of smoking bans, but did not add substantial information to our models including the basic measure of current smoking prevalence. We also added variables one at a time and in combination to control for sociodemographic (education, income, percentage by racial/ethnic group, percentage less than 24 years of age) and other state variations (percentage of US tobacco production). The addition of these variables had very little effect in terms of the magnitude of the coefficients or their levels of significance in the equations examining either changes in home bans or changes in work bans over 1993-1999. For the 1999 home ban equation, the media coefficient stayed significant and the tax variable obtained significance (for example, with the addition of age and some race variables). For the 1999 work ban equation, the tax and media coefficients in some cases became insignificant with the addition of control variables.

In summary, we found substantial growth in the rate of home and work smoking bans in the USA, but there is still considerable variation in these rates across states. The states with the highest ban rates tend to have lower smoking rates and stricter tobacco control policies. While further work is warranted, the results suggest that states with currently weak policies have the potential to motivate an increase in the number of homes and worksites choosing to implement bans. Any such increases in private smoking restrictions may yield indirect health benefits through reductions in second hand smoke. These benefits are often overlooked in evaluating the effects of tobacco control policies.

\section{ACKNOWLEDGEMENTS}

We would like to thank the Flight Attendants Medical Research Institute for their support to write this paper.

\section{Authors' affiliations \\ D T Levy*, E Romano, E A Mumford, University of Baltimore, Baltimore, Maryland, USA}

*Also Pacific Institute for Research and Evaluation

\section{REFERENCES}

1 Samet JM, Wang SS. Environmental tobacco smoke. In: Lippman M, ed. Environmental toxicants. J Wiley \& Sons, 1999.

2 National Cancer Institute. Health effects of exposure to environmental tobacco smoke: the report of the California Environmental Protection Agency. Smoking and Tobacco Control Monograph no. 10. US DHHS, National Institutes of Health, National Cancer Institute, 1999. (NIH Publication No 99-4645.)

3 US Environmental Protection Agency. Respiratory health effects of passive smoking: lung cancer and other disorders. Washington DC: Office of Health and Environmental Assessment, 1992.

4 Shopland DR, Gerlach KK, Burns DM, et al. State-specific trends in smoke-free workplace policy coverage: the current population survey tobacco use supplement, 1993 to 1999. J Occup Environ Med Aug 2001;43:680-6

5 Centers for Disease Control and Prevention. State-specific prevalence of current cigarette smoking among adults, and policies and attitudes about secondhand smoke-United States, 2000. MMWR Morb Mortal Wkly Rep 2001;50:1101-6.

6 Centers for Disease Control and Prevention. State-specific prevalence of current cigarette smoking among adults and the proportion of adults who work in a smoke-free environment-United States, 1999. MMWR Morb Mortal Wkly Rep 2000;49:978-82

7 Brownson RC, Davis JR, Jackson-Thompson J, et al. Environmental tobacco smoke awareness and exposure: impact of a statewide clean indoor air law and the report of the US Environmental Protection Agency. Tobacco Control 1995:4:132-8.

8 Brownson RC, Eriksen MP, Davis RM, et al. Environmental tobacco smoke: health effects and policies to reduce exposure. Annu Rev Public Health 1997; 18:163-85.

9 Biener L, Cullen D, Di ZX, et al. Household smoking restrictions and adolescents' exposure to environmental tobacco smoke. Prev Med 1997;26:358-63.

10 Borland R, Mullins R, Trotter L, et al. Trends in environmental tobacco smoke restrictions in the home in Victoria, Australia. Tobacco Control 1999:8:266-71.

11 Gilpin EA, Emery SL, Farkas AJ, et al. The California tobacco control program: a decade of progress, 1989-1999. La Jolla: University of California, San Diego, 2001

12 McMillen RC, Winickoff JP, Klein JD, et al. US adult attitudes and practices regarding smoking restrictions and child exposure to environmental tobacco smoke: changes in the social climate from 2000-2001. Pediatrics 2003;112(1 smoke: changes

13 US Department of Health and Human Services. Reducing tobacco use: A report of the Surgeon General. Atlanta, Georgia: Centers for Disease Control and Prevention, National Center for Chronic Disease Prevention and Health Promotion, Office on Smoking and Health, 2000.

14 Stillman F, Hartman A, Graubard B, et al. The American stop smoking intervention study. Conceptual framework and evaluation design. Eval Rev Jun 1999:23:259-80.

15 Farkas AJ, Gilpin EA, Distefan JM, et al. The effects of household and workplace smoking restrictions on quitting behaviours. Tobacco Control 1999;8:261-5.

16 Kegler MC, Malcoe LH. Smoking restrictions in the home and car among rural Native American and white families with young children. Prev Med 2002;35:334-42.

17 Pizacani BA, Martin DP, Stark MJ, et al. Household smoking bans: which households have them and do they work? Prev Med 2003;36:99-107.

18 Wakefield M, Banham D, Martin J, et al. Restrictions on smoking at home and urinary cotinine levels among children with asthma. Am J Prev Med 2000;19:188-92

19 Wakefield MA, Chaloupka FJ, Kaufman NJ, et al. Effect of restrictions on smoking at home, at school, and in public places on teenage smoking: cross sectional study. BMJ 2000;321:333-7.

20 US Department of Health and Human Services. The health consequences of involuntary smoking. A report of the Surgeon General, 1986. Rockville, Maryland: Public Health Service, Centers for Disease Control, 1986, (DHHS Publication No (CDC) 87-8398.)

21 Farrelly MC, Evans WN, Sfekas AE. The impact of workplace smoking bans: results from a national survey. Tobacco Control 1999;8:272-7.

22 Levy D, Friend K. A review of the literature on clean air laws: where do we go from here? Health Educ Res 2003;18:592-609.

23 Levy DT, Cummings KM, Hyland A. Increasing taxes as a strategy to reduce cigarette use and deaths: results of a simulation model. Prev Med 2000;31:279-86.

24 Levy DT, Friend K. A computer simulation model of mass media interventions directed at tobacco use. Prev Med 2001;32:284-94.

25 Levy DT, Friend K, Polishchuk E. Effect of clean indoor air laws on smokers: the clean air module of the SimSmoke computer simulation model. Tobacco Control 2001;10:345-51.

26 Orzechowski W, Walker RC. The tax burden on tobacco, historical compilation. Arlington, Virginia, 2000; volume 35.

27 Chriqui JF, Frosh M, Brownson RC, et al. Application of a rating system to state clean indoor air laws (USA). Tobacco Control 2002;11:26-34.

28 Mumford EA, Levy DT, Romano EO. Home smoking restrictions and the accuracy of individual reports. Am J Prev Med (in press).

29 Moskowitz J, Lin Z, Hudes E. The impact of California's smoking ordinances on worksite smoking policy and exposure to environmental tobacco smoke. Am J Health Promot 1999;13:278-81.

30 Norman GJ, Ribisl KM, Howard-Pitney B, et al. The relationship between home smoking bans and exposure to state tobacco control efforts and smoking behaviors. Am J Health Promot 2000;15:81-8. 